\section{O movimento da medicina psicossomática no Brasil: a trajetória teórica e institucional de Danilo Perestrello}

\section{Danilo Perestrello and the psychosomatic medicine movement in Brazil: from theory to institutional acceptance}

\author{
Carla Ribeiro Guedes ${ }^{i}$ \\ 'Professora, Departamento de Saúde e Sociedade/ \\ Instituto de Saúde Coletiva/Universidade Federal Fluminense. \\ Niterói - RJ - Brasil \\ orcid.org/0000-0002-5224-2592 \\ carla.rguedes@gmail.com
}

\section{Vanessa Maia Rangel ${ }^{i i}$}

ii Professora, Departamento de Saúde e Sociedade/ Instituto de Saúde Coletiva/Universidade Federal Fluminense. Niterói - RJ - Brasil

orcid.org/0000-0002-1899-1557

vanessamaiarangel@gmail.com

Kenneth Camargo Jr.iii

iii Professor, Departamento de Planejamento e Administração em Saúde/ Instituto de Medicina Social/Universidade do Estado do Rio de Janeiro. Rio de Janeiro - RJ - Brasil

orcid.org/0000-0003-3606-5853

kenneth@uerj.br

Recebido em 17 out. 2018

Aprovado em 28 jan. 2019.

http://dx.doi.org/10.1590/S0104-59702020000400006
GUEDES, Carla Ribeiro; RANGEL, Vanessa Maia; CAMARGO JR., Kenneth. O movimento da medicina psicossomática no Brasil: a trajetória teórica e institucional de Danilo Perestrello. História, Ciências, Saúde Manguinhos, Rio de Janeiro, v.27, n.3, jul.-set. 2020, p.803-817.

Resumo

Na década de 1950, surgia o movimento da medicina psicossomática no Brasil, tendo como protagonista o psiquiatra e psicanalista Danilo Perestrello. A configuração dessa proposta e a análise das estratégias construídas para a formação desse campo disciplinar são o objeto deste estudo. Desde o início, esse movimento foi marcado por um projeto teórico-institucional de refundação da medicina sobre bases psicanalíticas e de institucionalização. Em sua trajetória, Perestrello publicou artigos e livros que tinham como intuito formar um novo estilo de pensamento entre os médicos, bem como a ocupação de instituições estratégicas. Seu afastamento profissional, devido a uma grave doença em 1976, representou um fator desagregador do movimento psicossomático no contexto brasileiro.

Palavras-chave: medicina psicossomática; psicologia médica; Danilo Perestrello (1916-1989); trajetória teóricoinstitucional.

Abstract

In the 1950s, the psychosomatic medicine movement emerged in Brazil, led by psychiatrist and psychoanalyst Danilo Perestrello. This article analyzes the strategies developed to configure this proposal and establish this field of study. From the beginning, this movement was characterized by a plan to reformulate medicine based on psychoanalytic theory and obtain favorable reception in institutions. During his career, Perestrello published articles and books with the intention of establishing a new way of thinking among physicians and worked at strategic institutions. His withdrawal from professional work due to a serious illness in 1976 was a factor contributing to the fragmentation of the psychosomatic movement in Brazil.

Keywords: psychosomatic medicine; medical psychology; Danilo Perestrello (1916-1989); theoretical trajectory; institutional trajectory. 
A medicina psicossomática tem suas raízes históricas na década de 1930, nos EUA, em um movimento que enfocava as causalidades psíquicas do adoecimento a partir de formulações psicanalíticas. A difusão dessa nova perspectiva se deu graças aos trabalhos realizados no Instituto Psicanalítico de Chicago, por nomes como Franz Alexander (18911964), Georg Groddeck (1866-1934) e Helen Flanders Dunbar (1902-1959) (Birman, 1980; Matta, Camargo Jr., 2010).

Em fins da década de 1950, houve maior legitimidade dessa proposta, sobretudo por conta da repercussão dos trabalhos de Michael Balint (1896-1970), médico e psicanalista húngaro radicado no Reino Unido, discípulo de Sandor Ferenczi (1873-1933). Balint (1958) introduziu na medicina noções da teoria psicanalítica, amplamente divulgadas em seu livro O médico, seu paciente e a doença.

Essa abordagem visava modificar a relação médico-paciente, dando-lhe uma conotação mais humanizada, assim como construir um modelo para a etiologia das doenças, em que os fatores psíquicos fossem considerados elementos fundamentais na formação das enfermidades somáticas. Dessas matrizes surgiu um campo ainda hoje difuso, ora denominado "medicina psicossomática", ora "psicologia médica" (Camargo Jr. et al., 1999; Guedes, 2003).

Nesse mesmo período, surgiu no Brasil um movimento que tinha como protagonista Danilo Perestrello (1916-1989), psiquiatra e psicanalista formado em 1939 pela Faculdade de Medicina da Universidade do Brasil. Esse autor formulou as bases da medicina psicossomática no contexto brasileiro, ancorado em referenciais da teoria e da técnica psicanalíticas. Desde o início, os atores desse processo tinham um projeto político-institucional bastante claro: a formação de um campo disciplinar no Brasil, em especial no Rio de Janeiro, com a ocupação de espaços institucionais como a Sociedade Brasileira de Psicanálise do Rio de Janeiro (SBPRJ), a Santa Casa de Misericórdia e escolas médicas da cidade (Camargo Jr. et al., 1999).

Subjacente a esse projeto, localizamos a crítica ao reducionismo organicista da medicina hegemônica. Esse movimento, além de ter um projeto político-institucional, possuía o ambicioso objetivo de refundar a teoria e a prática médicas sobre bases mais amplas, embora subordinadas de forma evidente a uma visão essencialmente psicanalítica (Camargo Jr. et al., 1999; Guedes, 2003).

A configuração da proposta da medicina psicossomática ${ }^{1}$ e a análise das estratégias construídas por Danilo Perestrello para a formação desse campo disciplinar no Rio de Janeiro são o objeto deste estudo.

\section{Aspectos teórico-metodológicos}

Para abordar a constituição desse campo, suas práticas e seus saberes, optamos por um olhar epistemológico, com a análise da produção discursiva de Danilo Perestrello, dispersa em um amplo número de publicações (revistas especializadas, livros, periódicos de divulgação, manuais técnicos) com públicos-alvo e objetivos diversos, abarcando o período de 1941 a 1976 (ano em que foi acometido por uma doença incapacitante). Somado a isso, há um contexto histórico do qual esse campo faz parte que pretendemos abordar por meio de estudos sobre a história dos saberes psicológicos no Brasil e, em especial, no Rio 
de Janeiro (Facchinetti, Castro, 2015; Russo, 2005, 2008; Duarte, Russo, Venâncio, 2005; Schreiner, 2005; Duarte, 2013).

O eixo teórico epistemológico deste estudo se ancora em autores que, respeitando suas especificidades, procuraram dar conta da questão da produção do conhecimento. Por um lado, veremos o processo de construção de um campo disciplinar e suas interrelações, considerando o conceito de "campo" de Pierre Bourdieu (1983). Com a proposta do grupo de Danilo Perestrello de um projeto teórico-institucional para a formação do campo disciplinar da medicina psicossomática no Brasil, pretendeu-se produzir saberes, práticas e formas de organização política e científica no campo da psicanálise e da medicina. Além de uma disputa epistemológica, cognitiva, deu-se também uma disputa pelo mercado de ideias, até então dominado pelo discurso médico e seus corolários. Esse confronto, que é característico do campo científico, constituiu uma arena política em busca de prestígio, recursos e poder entre seus diversos atores (Bourdieu, 1983; Matta, Camargo Jr., 2010).

Por outro lado, a proposta epistemológica de Ludwik Fleck (1986) oferece uma importante contribuição aos estudos da produção de saber na medicina. Em A gênese e o desenvolvimento de um fato científico, Fleck realiza um estudo sobre o desenvolvimento histórico da sífilis e da reação de Wasserman, demonstrando como os "fatos científicos" são condicionados às circunstâncias históricas e culturais.

Fleck (1986) aponta para o caráter coletivo, interdisciplinar e cooperativo da investigação em medicina. O processo de fazer ciência é sempre coletivo e delimitado por estruturas sociológicas, históricas e culturais. Essa predisposição cognitiva é explicitada por meio de dois conceitos: o "coletivo de pensamento" e o "estilo de pensamento". O primeiro designaria "uma unidade social de uma comunidade de cientistas de um campo específico", enquanto o segundo é definido como "as pressuposições de acordo com um estilo sobre as quais o coletivo construiria seu edifício teórico" (Fleck, 1986, p.23).

O processo de conhecer é composto de indivíduos, que não têm consciência do estilo de pensamento coletivo que, quase sempre, exerce sobre seu pensamento uma coerção absoluta e contra o qual é sensivelmente impensável uma oposição (Fleck, 1986, p.87).

Não há um olhar que não esteja impregnado por pressuposições, pela mediação de um estilo de pensamento. A propensão a pensar e agir de determinada forma é a principal característica de um estilo de pensamento (Fleck, 1986).

O estilo de pensamento cria a realidade a partir de negociações incessantes entre os atores, negociações essas que vão progressivamente materializando os fatos sociais. A realidade é dotada de organizações e jogos interrelacionais nos quais o coletivo de pensamento se consolida em um contexto em que ideias e significações são compartilhadas: "tanto o coletivo de pensamento é nutrido pelos diferentes estilos de pensamento que o compõem quanto ao mesmo tempo possui a função de mediador desses estilos de pensamento, construindo-os" (Santos, Jacó-Vilela, 2009, p.191).

Neste artigo, interessa-nos perceber como se configurou o coletivo de pensamento da medicina psicossomática. Na trajetória da produção de conhecimento de Perestrello, podemos constatar a presença de alguns coletivos de pensamento: o higienismo, a psiquiatria, a psicanálise e a medicina psicossomática. Pretendemos analisá-los, procurando identificar as ideias que formam seus estilos de pensamento. 
Dessa forma, este estudo lança luz sobre as principais ideias que constituem cada um desses coletivos, e busca compreender as estratégias de configuração do campo disciplinar da medicina psicossomática.

\section{0 higienismo}

O estilo de pensamento vigente nas obras iniciais de Perestrello é permeado pela denominada "higiene mental", que consistia em uma mescla de teorias e práticas extraídas da medicina (em particular a saúde pública e a psiquiatria), da psicologia e da pedagogia. Seu marco de maior relevância foi a preocupação com a prevenção e a correção de transtornos mentais, e seus principais públicos-alvo eram: a criança, a família e a escola (Schreiner, 2005).

As primeiras produções textuais do autor se deram em formato de manuais: A quinta coluna contra a saúde, Sífilis e Almas infantis (Perestrello, 1941, 1943, 1946a), publicados pelo Serviço Nacional de Educação Sanitária do Ministério da Educação e Saúde, onde Perestrello atuava como médico. Em Almas infantis, o autor dá destaque à higiene mental, que "previne as doenças mentais, o crime e os vários desajustamentos da personalidade ao meio social, mas visa também e sobretudo à formação de seres mentalmente sãos, harmônicos e equilibrados" (Perestrello, 1946a, p.7). Perestrello ressalta a importância da higiene mental na infância, uma vez que é nos primeiros anos de vida que ocorre a formação da personalidade. Esse manual é organizado como uma série de orientações sobre educação infantil aos pais e aos professores.

A higiene mental foi definida como "moral universal do amanhã" pela Liga Brasileira de Higiene Mental, fundada em 1922, no Rio de Janeiro, pelo psiquiatra Gustavo Riedel (18821934). A proposta surgiu em um contexto em que a elite intelectual brasileira procurava construir um projeto de nação baseado na educação e na higiene. Na década de 1930, um grupo de psiquiatras liderou o movimento pela difusão dos preceitos eugênicos entre a população brasileira (Schreiner, 2005; Russo, 2008).

Duarte, Russo e Venâncio (2005) apontam que, no início do século XX, a ciência se afirmou como o meio para compreender e sanar os males da nação, buscando substituir os costumes ditados pela tradição por comportamentos e práticas informados pelo saber científico. Os discursos produzidos sobre educação e saúde constituíram as principais vias políticas na construção de uma sociedade que pretendia realizar um projeto modernizador e civilizatório, pautado por valores individualistas.

Perestrello aparece, nesse momento inicial de sua trajetória, como um atualizador de ideias e valores da época voltados para certa "ortopedia moral" da população, que configuravam os valores individualistas, baseados na ciência e capitaneados pelo Estado, representado pelo Ministério da Educação e Saúde (Duarte, Russo, Venâncio, 2005; Russo, 2005).

No entanto, ao analisar a trajetória do nosso personagem central, identificamos um afastamento desse estilo de pensamento. De acordo com Fleck (1986), o pensamento se modifica constantemente em conformidade com os sistemas de ideias que o circundam, sendo cada ideia pré-formada não individual, mas coletiva, de modo que fato e conhecimento têm um caráter altamente temporário. Dessa forma, podemos pensar que 
o ideário da higiene mental e sua associação com o processo modernizador/civilizador da sociedade brasileira, que tem seu apogeu da República Velha ao Estado Novo, deixam de representar um pensamento vigente no decorrer dos anos 1940, em prol de outros estilos de pensamento.

Como veremos ao longo de sua trajetória, Perestrello fará questão de se diferenciar e se afastar desse primeiro grupo de psiquiatras psicanalistas que fizeram parte da história da psicanálise no contexto brasileiro (Facchinetti, Castro, 2015; Duarte, Russo, Venâncio, 2005).

\section{A psiquiatria}

Danilo Perestrello ingressou na psiquiatria a partir de um concurso público, quando passou a trabalhar na Colônia Juliano Moreira, e defendeu em 1946 a tese A psiquiatria atual como psicobiologia para o concurso de Livre Docência de Psiquiatria na então Faculdade de Medicina da Universidade do Brasil.

Em sua tese (Perestrello, 1946b), ele apresenta algumas noções que podem ser identificadas como uma matriz das bases teóricas da medicina psicossomática, extraídas de ideias centrais de seu texto. São elas:

(1) Soma e psiquismo formam uma só unidade. Impõe-se a noção do homem como unidade psicossomática;

(2) O objeto da psiquiatria deve ser o indivíduo concreto, o são e o doente, em suas relações com o meio, e não as doenças;

(3) Não há hereditariedade sem ambiente, nem ambiente sem hereditariedade;

(4) Não há setor no organismo que possa ser concebido separadamente da psique;

(5) O psicobiológico pressupõe a biografia da pessoa. Essa biografia inclui experiências psíquicas passadas, suas disposições, tendências, seu patrimônio hereditário e questões ambientais;

(6) A unidade psicobiológica, o todo integrado ou pessoa, é uma unidade biopsicossocial;

(7) O diagnóstico psicobiológico deixa de ser nosológico para ceder lugar ao diagnóstico de personalidade enferma. Serão levados em consideração todos os fatos que, agindo em interdependência, constituem-se em fatores da doença, tais como disposições, conflitos, vivências intensas, fantasias etc.

Nessas noções podemos observar alguns componentes de suas principais ideias: todo/ totalidade/unidade, singularidade (expressas nas trajetórias pessoais), experiência (história de vida, biografia) e compreensão subjetiva (fantasias, desejos, conflitos etc.).

Duarte (2013) aponta que esses elementos estão presentes nas bases da psicanálise e da antropologia, e que são herdeiros da tradição filosófica romântica. Ambas as disciplinas têm em comum uma compreensão integral da experiência humana, ao contrário das ambições biomédicas de uma causalidade corporal linear.

De fato, nessa obra inaugural, Perestrello (1946b) se mostra um crítico contundente do modelo mecanicista da medicina então vigente: "o animismo, o vitalismo, o dualismo corpo-alma cartesiano, o personalismo, com a distinção entre indivíduo e pessoa, não podem ser aceitos. O homem aparece como um caso particular, como experimento da natureza e, pois, como todo integrado...". 
Defende, assim, a integração de diferentes dimensões para a compreensão do adoecer. Afirma que a psiquiatria é uma especialidade médica e que a medicina deve repousar na biologia, mas não se restringir a essa disciplina, visto que o homem, seu objeto de estudo, possui, além de anatomia e fisiologia, também psicologia e mantém relações com o ambiente físico e social. Chega, inclusive, a afirmar que o psiquiatra é metade médico e metade sociólogo, apesar de a dimensão social desaparecer no termo central de sua obra, a "psicobiologia".

Embora em sua tese o autor apresente os estudos de Dunbar (1943) e de Weiss e English (1944), o arcabouço teórico da medicina psicossomática ainda se encontra bastante difuso. De acordo com o modelo epistemológico de Fleck (1986), podemos encontrar nesse momento "protoideias" ou "pré-ideias", isto é, concepções iniciais vinculadas aos fatos científicos, porém ainda mal delineadas e muitas vezes obscuras. São imprecisas, com uma tendência à persistência de ideias que já estão infiltradas em um estilo de pensamento (Fleck, 1986).

Desse modo, termos como "psicobiologia", "unidade psicobiológica", "diagnóstico psicobiológico" e "psicobiólogo", utilizados amplamente em sua tese, podem ser vistos como uma forma de manutenção de ideias presentes no estilo de pensamento médico vigente. Ao mesmo tempo, é possível identificar conceitos e referências bibliográficas que apontam para a formação de um novo estilo de pensamento que se aproxima da psicanálise.

\section{A psicanálise}

A história da psicanálise no Rio de Janeiro reserva um importante capítulo que tem como personagem central Danilo Perestrello. Facchinetti e Castro (2015), no estudo "The historiography of psychoanalysis in Brazil: the case of Rio de Janeiro", mostram-nos que sua inserção institucional na psicanálise se inicia com a criação, em 1944, de um grupo de estudo psicanalítico nomeado Centro de Estudos Juliano Moreira. A formação desse grupo se deu em parceria com outros psiquiatras vinculados ao Serviço Nacional de Doença Mental que estavam insatisfeitos com o modo como a psicanálise era ensinada na Faculdade de Medicina por Henrique Roxo (1877-1969), catedrático de psiquiatria desde 1911 e responsável por introduzir a teoria freudiana em seus cursos.

Nesse mesmo período, em 1944 e 1945, um grupo de médicos, entre eles Danilo e sua esposa, Marialzira Perestrello (1916-2015), tentou trazer um psicanalista autorizado pela International Psychoanalytical Association (IPA) para dar início à formação dos psicanalistas cariocas. Sem sucesso, o grupo seguiu para a Argentina, para uma formação junto à Sociedade de Psicanálise de Buenos Aires. Em 1946, Perestrello iniciou seus estudos na Associação Psicanalítica Argentina (APA) e retornou ao Brasil como membro associado, em 1949 (Facchinetti, Castro, 2015; Russo, 2008).

Em seu retorno, Perestrello estabeleceu uma distinção entre seus predecessores, isto é, aqueles que disseminaram a psicanálise no Rio de Janeiro antes da aliança com a IPA, e os pioneiros que proporcionaram a formação psicanalítica no país com base nos preceitos da IPA (Facchinetti, Castro, 2015).

Facchinetti e Castro (2015) chamam a atenção para o fato de que essa distinção tinha o intuito de mostrar que os pioneiros eram mais importantes do que seus predecessores 
na definição do escopo e do estudo da psicanálise no Rio de Janeiro. De acordo com Perestrello (1976), o estágio anterior foi um período em que vários intelectuais escreveram sobre o assunto, representando o "selvagem", ou os "psicanalistas primitivos", mas que não ousaram praticar a psicanálise de uma forma selvagem. Essas afirmações fazem referência aos debates do campo internacional iniciados por Freud em 1910 (ver Freud, 2001). Segundo Perestrello, não era suficiente para ser um psicanalista estar familiarizado com alguns casos da psicanálise, os analistas precisavam se familiarizar com técnicas, que não podiam ser simplesmente adquiridas por meio dos livros, e sim como aprendizes de analistas mais experientes. Uma formação sem esse tipo de aprendizado colocava em risco os pacientes e a causa da psicanálise, e aos seus olhos era uma psicanálise "selvagem". A fundação da IPA, cujos membros declararam publicamente sua adesão, permitia negar a responsabilidade pelos procedimentos que outras pessoas adotavam e que nomeavam de "psicanálise".

Apoiado por esse texto, Danilo Perestrello se juntou ao grupo de seguidores de Freud que lutaram para manter a prática psicanalítica dentro dos padrões estabelecidos pela IPA, rejeitando assim todas as outras expressões teóricas e/ou práticas da psicanálise no Rio de Janeiro que se afastavam desses preceitos. Em 1957, o grupo ao qual Perestrello pertencia foi reconhecido pela IPA como Sociedade Brasileira de Psicanálise do Rio de Janeiro (SBPRJ) (Facchinetti, Castro, 2015; Russo, 2008).

Marialzira Perestrello (1987), com base na mesma perspectiva, definiu dois momentos da história da psicanálise no Rio de Janeiro: antes e depois da formação do grupo de estudo do qual ela participou. Sua intenção era apresentar os precursores do movimento psicanalítico no Rio de Janeiro e descrever a importância de cada um nos cenários médico e psiquiátrico da época. Dirigindo-se aos "precursores" do Rio de Janeiro, a autora considera que o primeiro grupo de psiquiatras realizou uma apropriação parcial da psicanálise e que, em vista disso, a psicanálise só passou a ser plenamente compreendida pelo grupo de estudos do qual ela era integrante (Facchinetti, Castro, 2015).

Facchinetti e Castro (2015, p.24) ressaltam que, nessa versão da história da psicanálise no Rio de Janeiro, os autores menosprezam o movimento que começou quase vinte anos antes da fundação do grupo de estudos de 1944: "Na verdade, o seu objetivo foi demonstrar como a nova abordagem do grupo de estudos em que ambos participaram foi crucial para a psicanálise desenvolver-se adequadamente, ampliar seu campo de influência e obter reconhecimento pela IPA".

É importante destacar que esse ponto de vista não é imparcial: seu objetivo foi dar crédito ao movimento de alinhamento com o modelo da IPA e demonstrar que a institucionalização da psicanálise pela IPA inaugurava a psicanálise no país. Nessas narrativas de Danilo e Marialzira Perestrello, o que se destaca é o envolvimento de suas próprias trajetórias profissionais e sua respectiva importância para a criação da história da psicanálise no Rio de Janeiro. Ambos se colocaram na posição de membros pioneiros e responsáveis pela disseminação da "verdadeira" psicanálise de Freud (Facchinetti, Castro, 2015).

Esse episódio nos permite ver com clareza o projeto teórico-institucional de Perestrello para a reconfiguração do campo disciplinar da psicanálise. Produziram-se formas de organização política e científica por meio da noção de análise didática fornecida pela IPA, e de institucionalização com a fundação da SBPRJ. Podemos acompanhar também a 
disputa pela narrativa oficial da história, pelo lugar de "pioneirismo", pelo direito e pelo monopólio de transmissão da psicanálise. Nesse cenário, fica evidente a arena política e o lugar desse grupo na busca por prestígio ao reivindicar para si a formação desse campo científico, relegando para segundo plano o conjunto de psiquiatras psicanalistas dos anos 1920, que foram inclusive responsáveis pelas primeiras traduções da obra freudiana.

A produção de conhecimento de Perestrello não se restringiu à narrativa da história da psicanálise. Na segunda metade dos anos 1940, a teoria psicanalítica passou a fazer parte de sua produção textual, com muitos artigos sobre a etiologia das doenças.

Esse tipo de estudo foi apresentado pelo autor pela primeira vez em 1946, no primeiro Congresso Interamericano de Medicina, com a conferência "Importância do fator psicológico na etiopatogenia da úlcera gastroduodenal". Nesse evento, identificamos a formação de um estilo de pensamento que pretendia pensar as bases psicanalíticas das doenças orgânicas, formuladas a partir das contribuições da teoria psicanalítica e da medicina psicossomática da Escola de Chicago.

No artigo, publicado um ano depois do Congresso Interamericano, após citar inúmeras teorias que procuram explicar a gênese da úlcera gastroduodenal, Perestrello (1947, p.16) chama atenção para o fator psicológico das enfermidades: "Somente agora, porém, com a medicina psicossomática, é que os mecanismos psicológicos começam a ser estudados mais aprofundadamente, graças, sobretudo, ao trabalho incessante da escola psicanalítica".

Centrado nas contribuições de Franz Alexander, o artigo focaliza os estudos realizados nos pacientes com úlcera e afirma que eles vivem uma situação de conflito, com dois grupos de tendências opostas: de um lado, o anseio de volta à situação infantil de dependência, submissão e passividade; de outro, a necessidade de se tornar independente e bastar a si próprio. O processo orgânico que leva à ulceração remonta ao primeiro estágio de evolução da libido, a fase oral, quando as funções de nutrição representam toda a fonte de prazer para a criança. O desejo de ser amado, cuidado, de receber e de depender de alguém está associado às funções de nutrição, mas como o ego adulto não pode admitir a volta às atitudes infantis, entram em cena os mecanismos regressivos, e o desejo de ser amado converte-se no desejo de ser alimentado. Assim, a úlcera péptica aparece como resultado do estímulo crônico do estômago "vazio". Sendo objeto constante de estímulo, o estômago vai se autodigerindo, à medida que se torna mais faminto de amor e ajuda.

Nesse texto, que pode ser considerado inaugural de um novo estilo de pensamento no contexto brasileiro, o autor alia a psicanálise e a medicina, mais especificamente as contribuições psicanalíticas para se pensar a enfermidade somática. Essa aliança marcará toda a sua obra com a denominada "medicina psicossomática".

Ao longo de sua carreira, Perestrello escreveu outros artigos sobre as enfermidades digestivas: "Enfermidades digestivas funcionais psicogênicas", "Distúrbios digestivos funcionais psicogênicos", "Atualidade da patologia digestiva psicossomática" e "Coisas da vida e da gastroenterologia" (Perestrello, 1958a, 1960a, 1960b, 1987e). Também abordou outras patologias orgânicas por meio de uma perspectiva psicossomática, como dores de cabeça (Perestrello, 1987d, 1954), pitiríase rósea (Perestrello, 1987a), obesidade (Perestrello, 1963) e doenças coronarianas (Perestrello, 1974a). 
Podemos observar que os artigos psicanalíticos das décadas de 1940, 1950 e 1960 trazem essa marca da busca de etiologias psíquicas para os fenômenos somáticos. Por exemplo, em "Estudo psicanalítico das dores de cabeça", de 1952, Perestrello desenvolve uma tese psicanalítica para explicar a causalidade das dores de cabeça; utiliza-se de casos clínicos para afirmar que a origem da cefalalgia está relacionada à "cena primária" do paciente; enfatiza que, seja na realidade ou na fantasia, suas pacientes tiveram o espetáculo do coito dos pais na cena primária, na primeira infância.

Os artigos também apresentam outro marco importante na obra de Perestrello: a psicanálise como uma contribuição para a renovação da clínica médica. A psicanálise de Sigmund Freud é apresentada como uma ferramenta que faltava para a transição paradigmática de uma velha clínica para uma nova medicina. Com a investigação psicanalítica é que se começou a poder solucionar as reações afetivas inadequadas que se traduzem em sintomas corporais. Pôde-se, portanto, penetrar na vida íntima do homem e compreender não só os fenômenos conscientes, mas os inconscientes.

Ele defende que a clínica médica se concentre no homem, em seus valores e em seu modo existencial. A compreensão da "pessoa toda" só é possível com o instrumento psicológico, cujos alicerces repousam na psicanálise. Também destaca a formação do gastroenterologista: se a maioria dos transtornos em gastroenterologia é funcional, os fatores emocionais estão em primeiro plano demandando um médico capacitado para lidar com a problemática psicológica do enfermo (Perestrello, 1958a, 1960a, 1960b).

Podemos constatar que o autor acredita ser necessária a formação de um novo médico: "o futuro especialista deveria possuir uma base psicológica. Antes de ser gastroenterólogo, o médico deveria ser psicólogo" (Perestrello, 1958a, p.52). Esse novo médico seria um híbrido médico-psicólogo, ou melhor, médico-psicanalista.

Nesse momento, é possível observar o projeto téorico-institucional de Danilo Perestrello tomando corpo: a formação de um arcabouço teórico psicanalítico que explique a etiologia das doenças, a teoria psicanalítica como um referencial para a formação de uma nova medicina e de um novo médico, tudo isso aliado à ocupação da SBPRJ.

Esse projeto ganha força e novos contornos com a emergência do campo da medicina psicossomática no contexto brasileiro, sendo Perestrello seu principal propagador e articulador.

\section{A medicina psicossomática}

Em 1951, em comunicação apresentada na terceira Reunião Anual da Sociedade Brasileira para o Progresso da Ciência, podemos encontrar as bases teóricas da medicina psicossomática no Brasil (Perestrello, 1987c).

Na construção desse estilo de pensamento está presente uma crítica à medicina vigente e à prática clínica hegemônica, além da ideia de que ocorria uma mudança gradual no paradigma médico organicista.

Na comunicação inaugural da reunião de 1951, Perestrello discorre sobre o pensamento dominante na clínica e nos estudos médicos, afirmando que esses apresentavam uma visão meramente orgânica da doença e baseada em uma lógica mecânica causal. Para ele, a modificação desse pensamento no cenário da medicina, adotando uma visão mais ampla do 
doente em sua totalidade, devia-se aos avanços da psicologia. As descobertas da psicologia e da fisiologia teriam levado o médico a compreender o doente com uma personalidade total, no ambiente físico e social que o cerca, e não "apenas como uma máquina que necessita de reparo neste ou naquele departamento isolado" (Perestrello, 1987c, p.168).

Assim, ele anuncia o advento de uma nova medicina, a medicina psicossomática, resultante de uma profunda revisão do conceito de enfermidade como processo local e da interpretação do organismo em termos exclusivamente fisioquímicos. Apresenta também o "paciente como pessoa" como o novo objeto da medicina, e a vida psíquica do paciente como o mais novo valor na compreensão da etiologia da enfermidade.

Perestrello (1987c) prossegue fazendo uma análise do cenário do campo médico e sua aderência à medicina psicossomática. Segundo ele, para determinado grupo, o ponto de vista psicossomático seria uma novidade passageira, sem maiores bases para poder persistir; para um segundo grupo, seria um novo nome para designar um ponto de vista tão velho quanto a própria medicina. O primeiro grupo, dizia, "não pouco numeroso", viu na nova formulação um exagero das "correntes psicogenistas", e esse referencial seria passageiro. Era um grupo com posicionamento organicista, de perspectiva dualista, adquirida por meio do aprendizado oficial, e que procurava negar ou ignorar os métodos da medicina psicológica.

$\mathrm{O}$ autor considera exceções os médicos que ainda negavam a evidência dos fatos psicossomáticos e afirma que, ainda assim, quase todos os que a aceitaram o fizeram sob restrições, vindo a engrossar o segundo grupo, que representava a maioria: o dos médicos que acreditavam que o pensamento psicossomático existe desde a antiguidade (Perestrello, 1987c). Esse coletivo teria migrado de uma abordagem dualista para uma interacionista.

Para Perestrello (1987c), o advento da medicina psicossomática produziu uma situação traumática para o médico com formação clássica. A rápida profusão de novos conhecimentos da psicossomática surpreenderam os médicos com formação tradicional sem o preparo técnico psicológico indispensável para enfrentá-la.

Em sua apresentação sobre a medicina psicossomática e em sua análise do cenário médico, percebemos um movimento parecido com o que foi produzido no âmbito da psicanálise. O autor pretende reescrever a história, trazendo a ideia de pioneirismo para si e para os médicos que incorporavam essa noção, e os predecessores, os médicos tradicionais, são apresentados como uma "exceção", como atrasados e constrangidos diante do avanço do campo.

Em 1958, Perestrello publicou o livro Medicina psicossomática, lançado como a obra inaugural desse campo no contexto brasileiro, e nele apresenta para um público mais amplo a proposta que havia introduzido em sua conferência inaugural em 1951.

O constructo teórico apresentado por ele pode ser sistematizado em seis princípios:

(1) O objeto de estudo do médico é o homem doente, e não a doença.

(2) Não há doença local, toda enfermidade é geral e acomete o indivíduo como um todo. Ao falar sobre indivíduo como um todo, não se pode fazer diferença entre o psíquico e o somático, pois não há perturbação na qual deixe de participar o fator psicológico.

(3) O indivíduo isolado é uma abstração, o indivíduo só pode ser concebido em seu ambiente. Ele ressalta que o ambiente do indivíduo, suas condições culturais, seus 
gostos, suas inclinações, seus problemas e dificuldades constituem parte essencial de sua vida.

(4) Os estados emocionais podem perturbar o funcionamento de qualquer órgão e são tão eficazes na produção de modificações somáticas quanto os estímulos físicos.

(5) Não são as preocupações conscientes, reais, mas os conflitos inconscientes os principais responsáveis pelos sintomas somáticos.

(6) Os distúrbios funcionais podem, pela continuidade ou intensidade, acarretar lesões estruturais. Não há mais um limite nítido que procure estabelecer a diferença entre "funcional" e "orgânico".

A transformação do estilo de pensamento da medicina organicista para uma medicina psicossomática passa a ser a principal tese defendida por Danilo Perestrello (1987c, 1987b, 1956, 1958a, 1958b ,1960a, 1960b) em sua produção teórica.

O ensino e a institucionalização da medicina psicossomática tornam-se as principais estratégias para a expansão desse campo no contexto brasileiro.

\section{O ensino e a institucionalização da medicina psicossomática}

Em seu projeto de refundar a medicina sobre novas bases, podemos identificar duas grandes estratégias empreendidas por Perestrello: a primeira relacionada ao ensino, e a segunda à institucionalização da medicina psicossomática.

Em 1951, Perestrello ministrou um curso acerca da medicina psicossomática em uma disciplina na cadeira de psiquiatria da faculdade de medicina da Universidade do Brasil, da qual era docente. No artigo "Sobre o ensino da medicina psicossomática", publicado em 1956 e redigido a partir da aula inaugural desse curso, Perestrello afirmava que a ideia de criar uma cadeira de psicologia médica vinha sendo objeto de discussão. O autor também defendia que no futuro toda a medicina seria psicossomática e que as várias disciplinas médicas - desde as básicas, como fisiologia, até as clínicas - se pautariam por essa orientação, não havendo necessidade de qualquer cadeira complementar. Afirmava, porém, que por enquanto era necessário operar a completa renovação da mentalidade médica: "Até lá, como etapa transitória, a instituição de uma nova cadeira, cujo nome poderá ser 'Medicina Psicossomática', 'Psicologia Médica' ou semelhante, com a finalidade de prover ao estudante de medicina conhecimentos psicológicos básicos" (Perestrello, 1987b, p.51).

Além do público universitário, Perestrello dirige-se também ao corpo médico, por intermédio de conferências e cursos. Dedica-se a ensinar a seus pares as bases da medicina psicossomática, a fim de que possam ser incorporadas pelos médicos em suas práticas clínicas.

Na conferência "A psicanálise e as doenças somáticas", proferida em 1954, Perestrello esclareceu que não há enfermidade na qual deixe de intervir o fator emocional (ver Perestrello, 1987c). Outra questão muito presente nos ensinamentos de Perestrello (1958a) aos médicos é a importância da construção de uma relação médico-paciente com base na teoria psicanalítica.

Em 1958, o projeto de institucionalização da medicina psicossomática ganhou ainda mais corpo com a fundação de um Centro de Medicina Psicossomática - que Perestrello 
também dirigia - na Santa Casa de Misericórdia, hospital-escola da Universidade do Brasil, serviço composto por médicos psicanalistas. Em 1965, sua trajetória teórico-institucional entrou em um período que Camargo Jr. et al. (1999) nomeiam como "implantação", visto que se inaugurou a Associação Brasileira de Medicina Psicossomática (ABMP), que tinha por objetivo principal "a promoção de uma nova atitude na assistência, educação e pesquisas médicas, a atitude psicossomática, a qual visava à integração dos elementos psicodinâmicos e biológicos da patologia e conformar a conduta assistencial dentro desse novo parâmetro" (Eksterman, 1992, p.30).

Na década de 1970, aliado a esse movimento de institucionalização, Perestrello (1974b) publicou A medicina da pessoa, que podemos considerar um marco para a formação de um novo estilo de pensamento entre os médicos. Trata-se de um livro com uma forte marca pessoal. No texto há vários relatos de situações clínicas em que o próprio autor foi protagonista como médico psicanalista. A obra sistematiza ideias que marcaram sua trajetória, como a defesa de uma prática médica clínico-humanística, tirando o foco da doença e lançando luz sobre o doente e a complexidade de seu sofrimento. Nela, Perestrello deixa claro seu projeto teórico: refundar a teoria e a prática médicas sobre bases mais amplas, embora evidentemente subordinadas a uma visão psicanalítica (Camargo Jr. et al., 1999; Guedes 2003).

A etapa final do período de implantação da medicina psicossomática teve dois eventos marcantes no ano de 1976: a criação da disciplina de psicologia médica no Rio de Janeiro e a doença incapacitante de Perestrello, candidato natural à cátedra.

\section{Considerações finais}

A doença de Danilo Perestrello, em 1976, marcou o fim de sua trajetória pessoal, porém não encerrou o projeto teórico-institucional empreendido pelo autor.

Camargo Jr. et al. (1999) apontam mais duas etapas desse projeto concebido por Perestrello: o de expansão e o de consolidação. O período de expansão (1976-1984) caracterizou-se pelo processo de abertura de regionais da ABMP em outras cidades fora dos núcleos originais e a realização de dois congressos com abrangência nacional. Essa fase teve como marco teórico o livro Concepção psicossomática: visão atual, de Julio Mello Filho (1979), que apresenta uma tentativa de compor um painel do campo.

O período de consolidação (1984 até a data de publicação do artigo de Camargo Jr. et al., 1999) foi marcado pela institucionalização de fato da disciplina de psicologia médica, presente em praticamente todas as faculdades de medicina do estado do Rio de Janeiro, e a consolidação da ABMP, com a organização de eventos regulares, mantendo-se, contudo, o número de regionais. A coletânea Psicossomática hoje, organizada por Julio de Mello Filho (1992), é considerada o marco teórico referente ao período. Por ser uma coletânea, não traz uma marca única, pois os vários trabalhos que a compõem são desiguais. Camargo Jr. et al. (1999) afirmam que essa produção teórica, de caráter fragmentário, aponta para uma aproximação com a própria organização do conhecimento médico contemporâneo em manuais de clínica médica, divididos em capítulos e "loteados" por autores de acordo com sua competência específica. 
Com isso, o ambicioso projeto teórico-institucional de Danilo Perestrello de transformação da prática médica parece se perder. Seu afastamento profissional, devido à sua grave doença, foi indicado por seus pares como um fator desagregador em todo o movimento psicossomático (Camargo Jr. et al., 1999; Guedes, 2003). Suas críticas ao modelo médico hegemônico, no entanto, ainda soam correntes e suas ideias encontram eco em propostas bem mais recentes, como as noções de clínica ampliada (Campos, 2003), de medicina centrada na pessoa (Stewart et al., 2010) e de humanização em saúde (Brasil, 2010).

Em estudo antropológico sobre a construção da identidade profissional, Bonet (2003) resgata a obra de Perestrello e propõe que a medicina de família seja uma "medicina da pessoa". Posteriormente, Nogueira e Guedes (2013) também recuperam essa noção no artigo "Da graduação biomédica à medicina de família: aprendendo a se tornar um médico da pessoa". Podemos ir um pouco mais longe e almejar que seu legado humanista se estenda, transformando médicos em "médicos da pessoa".

\section{NOTA}

${ }^{1}$ Em 1974, Perestrello renomeou sua proposta para "medicina da pessoa". Essa terminologia não foi adotada pelos demais atores e autores do movimento psicossomático.

\section{REFERÊNCIAS}

BALINT, Michael.

O médico, seu paciente e a doença. Rio de Janeiro: Atheneu. 1958.

BIRMAN, Joel.

Enfermidade e loucura: sobre a medicina das interrelações. Rio de Janeiro: Campus. 1980.

BONET, Octávio.

Os médicos da pessoa: um estudo comparativo sobre a construção de uma identidade profissional. Tese (Doutorado em Antropologia Social) - Universidade Federal do Rio de Janeiro, Rio de Janeiro. 2003.

BOURDIEU, Pierre.

O campo científico. In: Ortiz, Renato (Org.).

Pierre Bourdieu. São Paulo: Ática. 1983.

BRASIL.

Ministério da Saúde. Secretaria de Atenção à Saúde. Núcleo Técnico da Política Nacional de Humanização. Humaniza SUS: documento base para gestores e trabalhadores do SUS. Brasília: Editora do Ministério da Saúde. 2010.

CAMARGO JR., Kenneth et al.

Psicologia médica: um trajeto teórico e institucional. (Série Estudos em Saúde Coletiva, n.192). Rio de Janeiro: Uerj/IMS. 1999.

CAMPOS, Gastão Wagner de Sousa. Saúde paideia. São Paulo: Hucitec. 2003.
DUARTE, Luiz Fernando Dias.

Antropología y psicoanálisis: retos de las ciencias románticas en el siglo XXI. Revista Culturas PSI, v.1, p.45-63. 2013.

DUARTE, Luiz Fernando Dias; RUSSO, Jane; VENÂNCIO, Ana Teresa A. (Org.).

Psicologização no Brasil: atores e autores. Rio de Janeiro: Contra Capa Livraria. 2005.

DUNBAR, Helen Flanders.

Psychosomatic diagnosis. New York: Paul B. Hoeber. 1943.

EKSTERMAN, Abram.

Medicina psicossomática no Brasil. In: Mello Filho, Julio (Org.). Psicossomática hoje. Porto Alegre: Artes Médicas. 1992.

FACCHINETTI, Cristiana; CASTRO, Rafael Dias. The historiography of psychoanalysis in Brazil: the case of Rio de Janeiro. Dynamis, n.35, v.1, p.13-34. 2015.

FLECK, Ludwik.

La genesis y el desarrollo de un hecho científico. Madri: Alianza. 1986.

FREUD, Sigmund. Observations on "wild" analysis. Standard Edition. London: Vintage. 2001. 
GUEDES, Carla Ribeiro.

A psicologia médica na Universidade do Estado do Rio de Janeiro: um estudo de caso. Psicologia e Sociedade, n.15, v.1, p.161-181. 2003.

MATTA, Gustavo; CAMARGO Jr., Kenneth Rochel de.

O processo saúde-doença como foco da psicologia: as tradições teóricas. In: Spink, Mary Jane Paris (Org.). A psicologia em diálogo com o SUS. São Paulo: Casa do Psicólogo. 2010.

MELLO FILHO, Julio (Org.).

Psicossomática hoje. Porto Alegre: Artes Médicas. 1992.

MELLO FILHO, Julio.

Concepção psicossomática: visão atual. Rio de Janeiro: Tempo Brasileiro. 1979.

NOGUEIRA, Maria Inês; GUEDES, Carla Ribeiro. Da graduação biomédica à medicina de família: aprendendo a se tornar um médico da pessoa. Physis: Revista de Saúde Coletiva, n.23, v.2, p.439460. 2013.

PERESTRELLO, Danilo.

Sobre um caso de pitiríase rósea. Apresentado no $4^{\circ}$ Congresso de Neurologia, psiquiatria e higiene mental realizado em Recife, 1956. In: Perestrello, Danilo. Trabalhos escolhidos. Rio de Janeiro: Atheneu. p.167-170. 1987a.

PERESTRELLO, Danilo.

Sobre o ensino da medicina psicossomática. Adaptação da aula inaugural do curso equiparado de psicologia médica, professado aos alunos do quarto ano da Faculdade Nacional de Medicina, 1956. In: Perestrello, Danilo. Trabalhos escolhidos. Rio de Janeiro: Atheneu. p.50-61. 1987b.

PERESTRELLO, Danilo.

A psicanálise e as doenças somáticas.

Conferência de uma série pronunciada para

o Corpo Médico da Marinha de Guerra no

Hospital Central da Marinha, Rio de Janeiro, 1954. In: Perestrello, Danilo. Trabalhos escolhidos. Rio de Janeiro: Atheneu. p.35-49. 1987c.

PERESTRELLO, Danilo.

Estudo psicanalítico das dores de cabeça. Trabalho apresentado à Associação Psicanalítica Argentina em dezembro de 1952. In: Perestrello, Danilo. Trabalhos escolhidos. Rio de Janeiro: Atheneu. p.139-165. 1987d.

PERESTRELLO, Danilo.

Coisas da vida e da gastroenterologia. Conferência pronunciada na Sociedade Brasileira de Gastroenterologia e Nutrição em 1970. In: Perestrello, Danilo. Trabalhos escolhidos. Rio de Janeiro: Atheneu. p.99-118. 1987e.
PERESTRELLO, Danilo.

Contribuição ao estudo da história da psicanálise no Brasil. Revista Brasileira de Psicanálise, v.10, p.293-296. 1976.

PERESTRELLO, Danilo.

A joie de vivre dos coronarianos. Revista Brasileira de Medicina, v.31, n.12, p.396-399. 1974a.

PERESTRELLO, Danilo.

A medicina da pessoa. Rio de Janeiro: Atheneu. 1974b.

PERESTRELLO, Danilo.

Estudos psicológicos na obesidade. Arquivos

brasileiros de endocrinologia e metabologia, v.12, n.2, p.116-120. 1963.

PERESTRELLO, Danilo.

Distúrbios digestivos funcionais psicogênicos. Medicina-Cirurgia-Farmácia, n.287, p.91-99. 1960a.

PERESTRELLO, Danilo.

Atualidade da patologia digestiva psicossomática. Medicina Universitária, v.1, n.1, p.5-13. 1960b.

PERESTRELLO, Danilo.

Enfermidades digestivas funcionais

psicogênicas. Anais do V Congresso Argentino de Gastroenterologia. p.549-556. 1958a.

PERESTRELLO, Danilo.

A medicina psicossomática. Rio de Janeiro: Atheneu. 1958b.

PERESTRELLO, Danilo.

Curso de introdução à medicina psicossomática. Arquivos Brasileiros de Medicina Naval, n.59, p.159164. 1956.

PERESTRELLO, Danilo.

Headache and primal scene. The International Journal of Psycho-Analysis, v.35, parte 2, p.219223. 1954.

PERESTRELLO, Danilo. Importância do fator psicológico na etiopatogenia da úlcera gastroduodenal. Evolução Psiquiátrica, v.1, n.1, p.15-24. 1947.

PERESTRELLO, Danilo.

Almas infantis. (Coleção SPES). Rio de Janeiro: Serviço Nacional de Educação Sanitária. 1946a.

PERESTRELLO, Danilo.

A psiquiatria atual como psicobiologia. Tese

(Docência Livre de Psiquiatria) - Faculdade

Nacional de Medicina da Universidade do Brasil, Rio de Janeiro. 1946b.

PERESTRELLO, Danilo.

Sífilis. (Coleção SPES). Rio de Janeiro: Serviço

Nacional de Educação Sanitária. 1943. 
PERESTRELLO, Danilo.

Quinta coluna contra a saúde. (Coleção SPES). Rio de Janeiro: Serviço Nacional de Educação Sanitária. 1941.

PERESTRELLO, Marialzira.

História da sociedade brasileira de psicanálise do Rio de Janeiro: suas origens e fundação. Rio de Janeiro: Imago. 1987.

RUSSO, Jane.

O movimento psicanalítico brasileiro. In: JacóVilela, Ana Maria; Ferreira, Arthur Arruda Leal; Portugal, Francisco Teixeira (Org.). Rio de Janeiro: Nau. 2008.

RUSSO, Jane.

Júlio Porto-Carrero: a psicanálise como instrumento civilizador. In: Duarte, Luiz Fernando Dias; Russo, Jane; Venâncio, Ana Teresa A. (Org.). Psicologização no Brasil: atores e autores. Rio de Janeiro: Contra Capa Livraria. 2005.
SANTOS, Fabia Monica Souza; JACÓ-VILELA, Ana Maria.

O psicólogo no hospital geral: estilos e coletivos de pensamento. Paideia, n.43, v.19, p.189-197. 2009.

SCHREINER, Alexandre.

Uma aventura para o amanhã: Arthur Ramos e a neuro-higiene infantil na década de 1930. In: Duarte, Luiz Fernando Dias; Russo, Jane; Venâncio, Ana Teresa A. (Org.). Psicologização no Brasil: atores e autores. Rio de Janeiro: Contra Capa. 2005.

STEWART, Moira et al.

Medicina centrada na pessoa: transformando o método clínico. Porto Alegre: Artmed. 2010.

WEISS, Edward; ENGLISH, Oliver S.

Psychosomatic medicine. London: W. B. Saunders Comp. 1944. 